\title{
Association between physical fitness levels and quality of life in people with epilepsy
}

\author{
Sudhindra Vooturi ${ }^{1,}{ }^{*}$, Potharaju Anil ${ }^{2}$, Avinash Kandula ${ }^{2}$, Mir Mohammad Ali ${ }^{2}$, Sailakshmi Kalva ${ }^{2}$, Monica Yazala ${ }^{2}$, and Sita \\ Jayalakshmi ${ }^{1}$ \\ ${ }^{1}$ Department of Neurology, Krishna Institute of Medical Sciences, Minister Road, Secunderabad-500003, Telangana, India \\ ${ }^{2}$ Department of Physiotherapy, Krishna Institute of Medical Sciences, Minister Road, Secunderabad-500003, Telangana, India
}

\begin{abstract}
Background: The aim of the study was to investigate the association of physical fitness with mental health scores in persons with epilepsy from India.

Methods: One hundred and fifty three consecutive persons with epilepsy with seizures controlled on optimal AED dosages for the last two years, aged 18-60 formed study population. Data was collected included demographics, seizure control. Relevant data on QOL was be collected through a self-reported quality of life questionnaire, the SF-12 from which Physical component scores (PCS) and Mental component scores (MCS) were derived. Physical fitness evaluation included: Body mass index, supervised six minute walk test and stepper test.
\end{abstract}

Results: The mean age of the cohort was $25.5 \pm 9.6$ years with $82(53.5 \%)$ men. The mean body mass index was $29.6 \pm 6.4$. The average distance walked in six minute walk test was $387.0 \pm 73.8$ meters and the average on a stepper test in a minute was $28.1 \pm 9.2$ steps. The average score on PCS of SF-12 questionnaire was $46.3 \pm 7.7$ and on MCS was $45.8 \pm 10.4$. There was no significant correlation between score on MCS and the measured physical fitness variables. However, both distance walked in six minute walk test and performance on stepper test showed significant correlation with PCS.

Conclusion: Simple tests like six minute walk test, one-minute stepper test may help to determine physical fitness scores in people with epilepsy. Although the current study did not show an association between mental and physical fitness scores, further robust trials are required to evaluate the same.

Keywords: Epilepsy; physical activity; fitness; six minute walk test; quality of life

*Corresponding author: Dr. Sudhindra Vooturi, Department of Neurology, Krishna Institute of Medical Sciences, Minister Road, Secunderabad-500003, Telangana, India. Tel.: +917702156965; Fax: +91-40-27814499; Email: sudhindragupta@gmail.com

Received 22 July 2019; Revised 3 September 2019; Accepted 11 September 2019; Published 19 September 2019

Citation: Vooturi S, Anil P, Kandula A, Ali MM, Sailakshmi K, Yazala M, Jayalakshmi S. Association between physical fitness levels and quality of life in people with epilepsy. J Med Sci Res. 2019; 7(4):99-102. DOI:

http://dx.doi.org/10.17727/JMSR.2019/7-17

Copyright: (c) 2019 Vooturi S et al. Published by KIMS Foundation and Research Center. This is an open-access article distributed under the terms of the Creative Commons Attribution License, which permits unrestricted use, distribution, and reproduction in any medium, provided the original author and source are credited. 


\section{Introduction}

Around 65 million people across the world live with epilepsy $[1,2]$. It is well known that people with epilepsy (PWE) have higher incidence and prevalence of depression, anxiety thus leading to a lower quality of life (QOL) scores than general population [3-10]. Until recently, PWE have not been advice in physical exercise/ activity partly because of overprotection, fear, and ignorance about the risks and benefits of physical activity practice $[11,12]$. As a result, not surprisingly, trials, which compared physical fitness in PWE with the general population, reported worse physical fitness in PWE [13-16].

However, it is well established that physical activity practice promotes several health benefits especially in patients with chronic diseases, where, physical activity practice reduces the levels of depression [17] and anxiety [18] and improves quality of life [19]. Moreover, studies done in western, developed countries, have reported a positive association between being physical activity and reduction in depression/ anxiety in PWE reported positive results for the physically active [20-23]. However, very little to sparse literature on role of physical fitness and QOL in PWE from developing countries has been reported in literature. This is important as nearly $80 \%$ of PWE live in developing and low to middle income countries [24]. Therefore, the aim of this study was to verify the association between physical fitness levels and quality of life in PWE in tertiary referral center in South-India.

\section{Methodology}

Consecutive persons with epilepsy with seizures controlled on optimal AED dosages for the last two years, attending the Out-Patient Epilepsy Clinic of Krishna Institute of Medical Sciences, Secunderabad, 153 subjects aged 18-60 years were recruited after obtaining an informed consent. The study was approved by Institutional Ethics Committee. Patients with cognitive or behavioral problems, musculosketetal or inability to do a six minute walk test and failure to obtain an informed consent formed the exclusion criteria.

Data was collected using a standard form for the following information: demographics, antiepileptic drug (AED) profile, seizure control and remission. Relevant data on QOL was be collected through a selfreportedquality oflife questionnaire, theSF-12. Based on the rating on the 12-point SF-12 scores, Physical component scores (PCS) and Mental component scores (MCS) were derived for each patient, using a validated equation. For an assessment of physical fitness, all the patients underwent comprehensive assessment for: Body mass index (BMI) based on WHO guidelines, supervised Six minute walk test and stepper test.

\section{Statistical analysis}

After ensuring the homogeneity of data, all continuous variables were expressed as mean \pm standard deviation; whereas all categorical variables were expressed at percentages. Association between MCS scores with PCS scores, distance walked in six minutes, score on one-minute stepper test and BMI was evaluated using Pearsons and Spearman correlation. A $\mathrm{p} \leq 0.05$ was considered significant. All statistical analysis was done using Statistical Package for Social Sciences (SPSS), version 20.0 for windows, IBM Computers, New York, USA.

\section{Results}

The mean age of the cohort was $25.5 \pm 9.6$ years with 82(53.5\%) men. The mean body mass index was 29.6 \pm 6.4 . The average distance walked in six minute walk test was $387.0 \pm 73.8$ meters and the average number of steps done on a stepper test in a minute was $28.1 \pm 9.2$ steps. The average score on PCS of SF12 questionnaire was $46.3 \pm 7.7$ and on MCS was 45.8 \pm 10.4 . The correlation analysis between the study variables and PCS and MCS, there was no significant correlation between score on MCS and the measured physical fitness variables. However, both distance walked in six minute walk test and performance on stepper test showed significant correlation with PCS. Moreover, age and BMI were not associated either with PCS or with MCS, Table 1.

Table 1: Association between study variables ( $\mathrm{n}=153)$.

\begin{tabular}{|clcc|}
\hline S. & Variable & $\begin{array}{c}\text { Correlation } \\
\text { No }\end{array}$ & $\begin{array}{c}\text { Correlation } \\
(r) \text { with } \text { PCS }\end{array}$ \\
\hline 1 & Age (years) & -0.164 & -0.007 \\
2 & $\begin{array}{l}\text { Distance walked in six } \\
\text { minutes (metres) }\end{array}$ & $0.359^{*}$ & 0.01 \\
3 & $\begin{array}{l}\text { Steps on stepper in one } \\
\text { minute }\end{array}$ & $0.281^{*}$ & 0.175 \\
4 & Body mass index & -0.06 & -0.031 \\
\hline
\end{tabular}

* indicates significant $(\mathrm{p}<0.05)$ correlation. PCS $=$ Physical Component Score on SF-12, MCS = Mental Component Score on SF-12. 
On evaluating number of PWE with low PCS and MCS scores on SF-12 (Figure 1), a cut off of 50 was utilized. On PCS, 93 (60.7\%) scored low on of which 47 (50.5\%) were men. Whereas on MCS, 95 (62.0\%) scored low, of which 48 (50.6\%) were men.

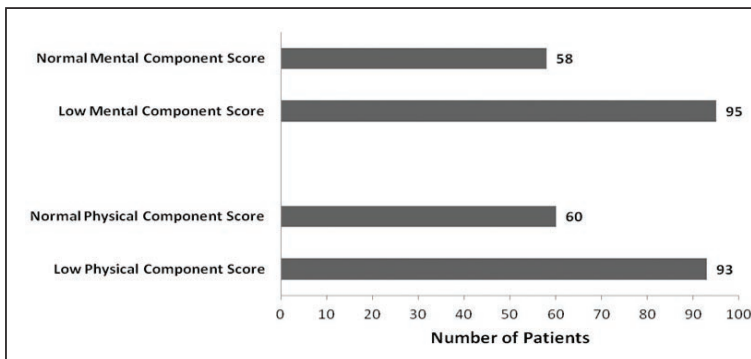

Figure 1: Scoring trends on SF-12 questionnaire.

\section{Discussion}

The presentstudy aimed to investigatethe association among quality of life and physical fitness levels in people with epilepsy. We report that the PCS score of SF-12 showed a positive association with physical fitness levels showed by PWE in distance walked in six minute walk test and steps taken in one-minute stepper test. However, similar correlations were not observed with MCS scores in the study population. Nearly one-third of PWE in the current study showed low scores on SF-12 and the low scores were equally distributed among genders.

It has been previously suggested that life conditions for PWE may be responsible for higher prevalence of low QOL scores in people with epilepsy [3], this may perhaps be the explanation for our finding that nearly one-third of our study population score low in SF-12. Existing literature shows a linear trend between physical activity and QOL in PWE, since majority of our study population had low scores on PCS, their MCS scores might have been influences.

In the past, several mechanisms have supported the positive changes promoted by physical activity on mental health. These mechanisms included psychological, physiological and neurophysiological. Encouragingly, higher the level of physical activity and has been associated with higher the quality of life by McAuley et al. [22] in an randomized control trial of PWE were lifestyle modification was chosen intervention. The scope of the current study, did not include randomization of patient groups for the data analysis done.
This is the first study in India to evaluate trend for physical fitness levels with mental health in PWE. Although there is a biological plausibility of an association between the physical activity and mental health variables, this cross-sectional study may not be an ideal design to verify the cause and effect relationship. More studies are needed, mainly randomized clinical trials, to establish the cause and effect relationship.

\section{Conclusion}

Simple tests like six minute walk test, one-minute stepper test may help to determine physical fitness scores in people with epilepsy. In India, nearly onethird of people with epilepsy have low physical and mental component scores. Although the current study did not show an association between mental and physical fitness scores, further robust trials are required to evaluate the same.

\section{Acknowledgement}

The data in obese persons with epilepsy has been done as part of PhD Degree of Dr. Sudhindra Vooturi under Dr. NTR University of Health Sciences, Vijayawada, Andhra Pradesh.

\section{Conflict of interest}

Authors declare no conflict of interest.

\section{References}

[1] Thurman DJ, Beghi E, Begley CE, Berg AT, Buchhalter JR, et al. Standards for epidemiologic studies and surveillance of epilepsy. Epilepsia. 2011; 52(Suppl 7):2-26.

[2] Fisher RS, Acevedo C, Arzimanoglou A, Bogacz A, Cross JH, et al. ILAE official report: a practical clinical definition of epilepsy. Epilepsia. 2014; 55(4):475-482.

[3] Hirtz D, Thurman DJ, Gwinn-Hardy K, Mohamed M, Chaudhuri AR, et al. How common are the "common" neurologic disorders? Neurology. 2007; 68(5):326-337.

[4] Boylan LS, Flint LA, Labovitz DL, Jackson SC, Starner K, et al. Depression but not seizure frequency predicts quality of life in treatment-resistant epilepsy. Neurology. 2004; 62(2):258-261.

[5] Cramer JA, Blum D, Reed M, Fanning K. The influence of comorbid depression on quality of life for people with epilepsy. Epilepsy Behav. 2003; 4(5):515-521.

[6] Loring DW, Meador KJ, Lee GP. Determinants of quality of life in epilepsy. Epilepsy Behav. 2004; 5(6):976-980.

[7] Spencer SS. Seizures and epilepsy. In: Goldman L, Ausielo D, editors. Cecil Medicine. Philadelphia: Elsevier/saunders; 2009. p. 2676-2686.

[8] Gaspari CN, Guerreiro CA. Modification in body weight associated with antiepileptic drugs. Arq Neuropsiquiatr. 2010; 68(2):277-281. 
[9] Petty SJ, O’Brien TJ, Wark JD. Anti-epilepticmedication and bone healthy. Osteoporos Int. 2007; 18(2):129-142.

[10] Zeng K, Wang X, Xi Z, Yan Y. Adverse effects of carbamazepine, phenytoin, valproate and lamotrigine monotherapy in epileptic adult Chinese patients. Cli Neurol Neurosurg. 2010; 112(4):291-295.

[11] Pimentel J, Tojal R, Morgado J. Epilepsy and physical exercise. Seizure. 2015; 25:87-94.

[12] Capovilla G, Kaufman KR, Perucca E, Moshé SL, Arida RM. Epilepsy, seizures, physical exercise, and sports: a report from the ILAE Task Force on Sports and Epilepsy. Epilepsia 2016; 57(1):6-12.

[13] Jalava M, Sillanpää M. Physical activity, health-related fitness, and health experience in adults with childhood-onset epilepsy: a controlled study. Epilepsia. 1997; 38(4):424429.

[14] Nakken KO. Physical exercise in outpatients with epilepsy. Epilepsia. 1999; 40(5):643-651.

[15] Wong J, Wirrel E. Physical activity in children/teens with epilepsy compared with that in their siblings without epilepsy. Epilepsia 2006; 47(3):631-639.

[16] Lee IM, Shiroma EJ, Lobelo F, Puska P, Blair SN, et al. Effect of physical inactivity on major non-communicable diseases worldwide: an analysis of burden of disease and life expectancy. Lancet. 2012; 380(9838):219-229.

[17] Conn VS. Depressive symptom outcomes of physical activity interventions: metaanalysis findings. Ann Behav Med. 2010; 39(2):128-138.

[18] Khanzada FJ, Soomro N, Khan SZ. Association of physical exercise on anxiety and depression amongst adults. J Coll Phys Surg Pak. 2015; 25(7):546-548.

[19] Pucci GC, Rech CR, Fermino RC, Reis RS. Association between physical activity and quality of life in adults. Rev Saúde Pública. 2012; 46(1):166-179.

[20] Han K, Choi-Kwon S, Lee S. Leisure time physical activity in patients with epilepsy in Seoul, South Korea. Epilepsy Behav. 2011; 20(2):321-325.

[21] de Lima C, de Lira CAB, Arida RM, Andersen LM, Matos G, et al. Association between leisure time, physical activity, and mood disorder levels in individuals with epilepsy. Epilepsy Behav. 2013; 28(1):47-51.

[22] McAuley JW, Long L, Heise J, Kirby T, Buckworth J, et al. A prospective evaluation of the effects of a 12 -week outpatient exercise program on clinical and behavioral outcomes in patients with epilepsy. Epilepsy Behav. 2001; 2(6):592600.

[23] Häfele CA, Freitas MP, Rombaldi AJ. Physical exercise effects on epilepsy in humans: a systematic review. Rev Neuroscien. 2015; 23(3):328-336.

[24] Kvalsund MP, Birbeck GL. Epilepsy care challenges in developing countries. Curr Opin Neurol. 2012; 25(2):179186. 